\title{
Variations in soil moisture and their impact on land-air interactions during a 6-month drought period in Taiwan
}

\author{
Fang-Yi Cheng ${ }^{*}$ (i) and Yi Chen
}

\begin{abstract}
This work is a follow-up study to Lin and Cheng (J Hydrometeorol 17:1337-1355, 2016). In our previous study, the Weather Research and Forecasting model was applied to investigate the impact of soil moisture initialization and soil texture on land-air interactions for a short-term 1-month period, in which two typhoons hit Taiwan and the atmospheric condition were wet. In this study, we extend the simulation period to 6 months and target a drought period. The simulation period is from October 1, 2014 to March 31, 2015. During this study period, a lack of rain caused the drought and strict water rationing was enforced in Taiwan. The study objectives are (1) to understand the effect of soil moisture initialization and soil texture on land-air interactions during the 6-month drought period and (2) to identify the distinction between the previous study, where the atmospheric condition was wet, and the current 6-month drought period. Compared to the previous 1-month simulation, the land-air interactions are strengthened in the 6-month drought period, showing the enhanced impact of soil moisture variations on the surface heat flux, air temperature, and local circulation. In addition, the evapotranspiration process is strengthened in this study, indicating that the land-air interactions are significant when the atmospheric condition is dry. A soil moisture-limited evapotranspiration regime was identified in the previous 1-month wet period study, with the soil moisture strongly constraining the evapotranspiration. However, in this study, the evapotranspiration process can be independent of the soil moisture content, once the soil moisture is lower than the wilting point.
\end{abstract}

Keywords: Soil moisture variations, Land-air interaction, WRF-Noah, Drought, Evapotranspiration

\section{Background}

Soil water content is an important parameter that affects water and energy cycles and the land-air interactions. It modulates the partition of total available energy into sensible heat fluxes (SHF) and latent heat fluxes (LHF) at the land surface, and influences the near-surface atmospheric conditions (Seuffert et al. 2002; Hung et al. 2014). LeMone et al. (2007) analyzed data from a flux tower, radar wind profiler and aircraft from the May-June 2002 International $\mathrm{H}_{2} \mathrm{O}$ Project (IHOP_2002) and the April-May 1997 Cooperative Atmosphere Surface Exchange Study (CASES-97). They found that soil moisture affects the relative magnitude of SHF and LHF.

\footnotetext{
${ }^{*}$ Correspondence: bonniecheng18@gmail.com

Department of Atmospheric Sciences, National Central University, No.

300, Chun-Da Rd, Chung-Li City, Tao-Yuan County, Taiwan
}

Various studies have indicated that the interaction between the land surface and the atmosphere is believed to be strong during drought periods and there is also a strong soil moisture-precipitation feedback loop. Zaitchik et al. (2012) indicated that positive soil moistureprecipitation feedbacks can intensify heat and prolong drought under the conditions of a precipitation deficit. In Meng and Shen (2014), the observational evidence indicates that soil moisture had an influence on the hot extremes and the daily temperature range in eastern China. It was also suggested that the previous drier surface conditions might intensify summer hot extremes and could potentially be used to predict extreme heat waves.

Soil moisture is an important source of atmospheric water vapor through the evapotranspiration (ET) process, including plant transpiration and bare soil evaporation. ET is a major component of the continental water 
cycle, as it returns as much as $60 \%$ of the water back to the atmosphere (Oki and Kanae 2006).

In Koster et al. (2004) and Seneviratne et al. (2006), two main ET regimes are defined: a soil moisture-limited regime and an energy-limited regime. In the energy-limited ET regime, when the soil moisture is above a given critical soil moisture value, ET is independent of the soil moisture content. Below the critical soil moisture, the soil moisture constrains the ET (soil moisture-limited ET regime). When the soil moisture is lower than the wilting point $\left(\theta_{\text {wilt }}\right)$, no further ET takes place. Seneviratne et al. (2010) defined a climate dry/wet regime, where the soil moisture is higher than the critical soil moisture value and lower than $\theta_{\text {wilt }}$, and soil moisture does not impact ET. When the soil moisture is between $\theta_{\text {wilt }}$ and the critical soil moisture value, the soil moisture strongly constrains ET and precipitation could be affected by soil moisture anomalies. The critical soil moisture level typically lies between $\theta_{\text {wilt }}$ and the field capacity, and is typically equal to ca. $50-80 \%$ of field capacity. Brubaker et al. (1993) indicated that the precipitation of a region could be supplied by ET from the land surface, indicating the importance of land-surface processes in the water balance. Savenije (1995) analyzed moisture recycling over the Sahel region and found that more than $90 \%$ of rainfall is from the recycling of moisture through ET. Wythers et al. (1999) proposed that evaporation is related to changes in the resistance to evaporation in a particular soil type, the amount of energy available to drive the evaporative process and the amount of water available to evaporate.

The mean rainfall per year in Taiwan is $\sim 2500 \mathrm{~mm}$ (CWB 1991); however, most of the rainfall is rapidly lost to the ocean due to the steep mountains in Taiwan. In addition, the rainfall in Taiwan tends to cause zonal or seasonal drought because of the uneven season rainfall distribution through most of the island (the northeastern part of Taiwan is an exception). The major source of rainfall is concentrated during the Mei-Yu season (May-June) and the typhoon season (July to October). On average, $90 \%$ of the annual precipitation falls in the wet season (May-October), with the remaining 10\% in the dry season (October-April) (Yu et al. 2002). Yu et al. (2006) concluded that rainfall in northern and eastern Taiwan increased on various time scales, but in central and southern Taiwan, it decreased. However, only during the dry season in central Taiwan and the typhoon season in southern Taiwan was the variation significant.

In our previous study (Lin and Cheng, 2016), the Weather Research and Forecasting (WRF) model was applied to investigate the impact of soil moisture initialization and soil texture on land-air interactions for a short-term 1-month period, in which two typhoons hit
Taiwan. The current work is a follow-up study to Lin and Cheng (2016). Here, we extend the simulation time to a 6-month drought period.

The purpose of this study is to investigate the impact of soil moisture variations on the land-surface hydrologic process, particularly focusing on a drought period in Taiwan. The study period is from October 1, 2014 to March 31, 2015. During this study period, a lack of rain caused the drought, resulting in strict water rationing being enforced in Taiwan. A detailed description of the episode is discussed in the following section. The objectives are (1) to understand the effect of soil moisture initialization and soil texture on land-air interactions during the 6-month drought period and (2) to identify the distinction between the previous study, where the atmospheric condition was wet, and the current 6-month drought period.

\section{Description of study period and model configuration}

The study period is from October 1, 2014 to March 31, 2015. During this study period, a lack of rain caused the drought and the water supply situation became urgent as Taiwan received the lowest rainfall since 1947. In response, the government in Taiwan made a two-phase water-rationing plan for the water shortage and water rationing was enforced from January 2015 until May 2015 when the Mei-Yu season begins to bring rain.

Starting from October and continuing to the following April, maintaining sufficient water levels in the reservoirs depended on the arrival of sporadic cold fronts that typically last $1-3$ days. During the study episode, the frontal passage was short, and most fronts did not bring sufficient rainfall, in addition to the precipitated rain not falling into the reservoir area. Furthermore, before the drought period, typhoons failed to bring sufficient rainfall. As a result of this phenomenon, a serious drought occurred in Taiwan. Figure 1 shows the observed accumulated rainfall from October to the March next year for years 2010-2014. The data are from Central Weather Bureau surface weather stations. It can be seen that the accumulated rainfall in this study period is extremely low compared to other years.

The WRF meteorological model (Skamarock 2008) version 3.7 was deployed to provide the meteorological data sets. Figure 2 identifies the simulation domain. The WRF configuration includes four nested domains with horizontal grid spacings of $81,27,9$, and $3 \mathrm{~km}$. Vertically, there are 49 sigma levels from the surface to the model top set at $100 \mathrm{hPa}$. The simulations started at $0000 \mathrm{UTC}$ 1 October 2014 and ended at 2300 UTC on 31 March 2015 , with a 24-h spin-up time and a simulated length of 6 months. The initial and boundary conditions for 


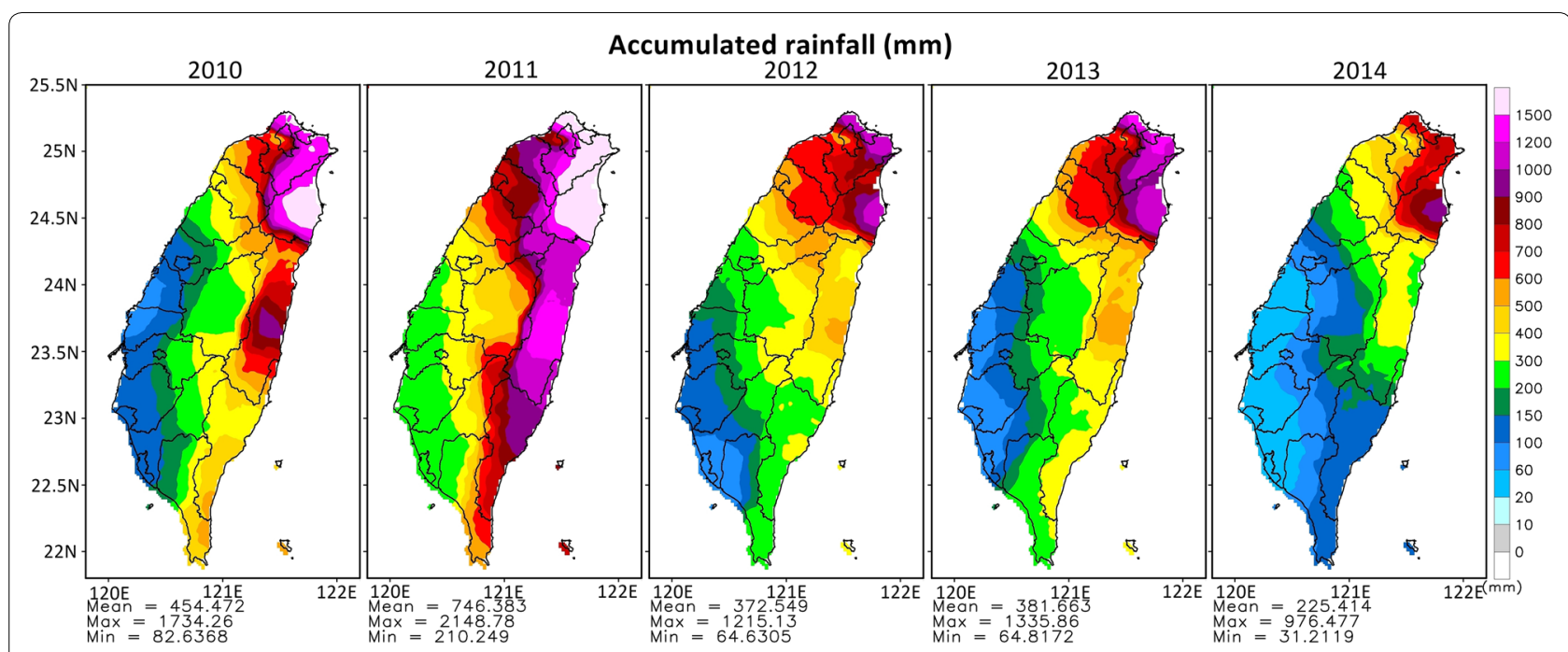

Fig. 1 Accumulated rainfall (mm) from October to the March next year for years 2010-2014

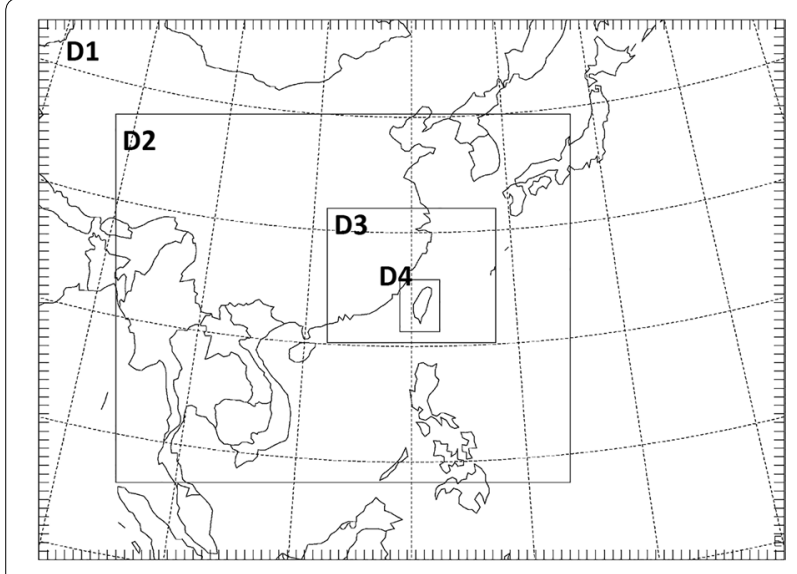

Fig. 2 WRF simulation domain

pressure, water vapor, temperature, and wind are from the NCEP FNL data at a $1^{\circ}$ grid spacing; in addition, the analysis nudging approach was applied above the boundary layer for wind, temperature, and water vapor to allow for large-scale forcing to be used to nudge the model simulation towards the reanalysis field and the nudging is applied every $6 \mathrm{~h}$. The physical packages applied for the WRF simulations follow Lin and Cheng (2016). The Noah LSM (Chen and Dudhia 2001) was chosen for the simulation of the surface ET and run-off processes.

In our previous study (Lin and Cheng 2016), the WRF meteorological model with the Noah land-surface model was applied to investigate the impact of soil moisture initialization and soil texture on land-air interactions for a short-term 1-month period in Taiwan. Instead of using the National Centers for Environmental Prediction (NCEP) Final (FNL) Operational Global Analysis data, soil moisture from the Global Land Data Assimilation System (GLDAS; Rodell et al., 2004) was utilized to provide the soil moisture initialization process. In addition, updated soil textures based on field surveys (Leung and Chen 1957) in Taiwan were adopted for WRF model. The previous study of a 1-month simulation focused on the short-term weather events and sub-seasonal time scale, which included two typhoon-induced precipitation episodes and a series of clear-sky days (Lin and Cheng, 2016). In this study, we extended the simulation period to 6 months and discussed the soil moisture variations and their impact on the land-air exchange process, particularly focusing on a drought period.

Following the setup of Lin and Cheng (2016), the $0.25^{\circ} \times 0.25^{\circ} 3$-h GLDAS data produced by the Noah model was used to initialize the soil conditions for the WRF model and was compared with the simulation that was driven by NCEP FNL data. The updated soil textures collected based on field investigations were used to provide a better resolution of soil states. Figure $3 \mathrm{a}$, b shows the original FAO soil textures used in the WRF model and the updated soil textures, respectively, at a $3-\mathrm{km}$ resolution in area of Taiwan. Figure 3c, d shows the porosity based on the look-up table of the default and updated soil type, respectively, with Fig. 3e giving the corresponding difference (a positive value indicates higher from the updated soil data). Figure $3 \mathrm{f}-\mathrm{h}$ shows the distributions of $\theta_{\text {wilt }}$.

Three WRF sensitivities were conducted. The first simulation was conducted without any update (WRFbase), for which the initial soil moisture was provided by 

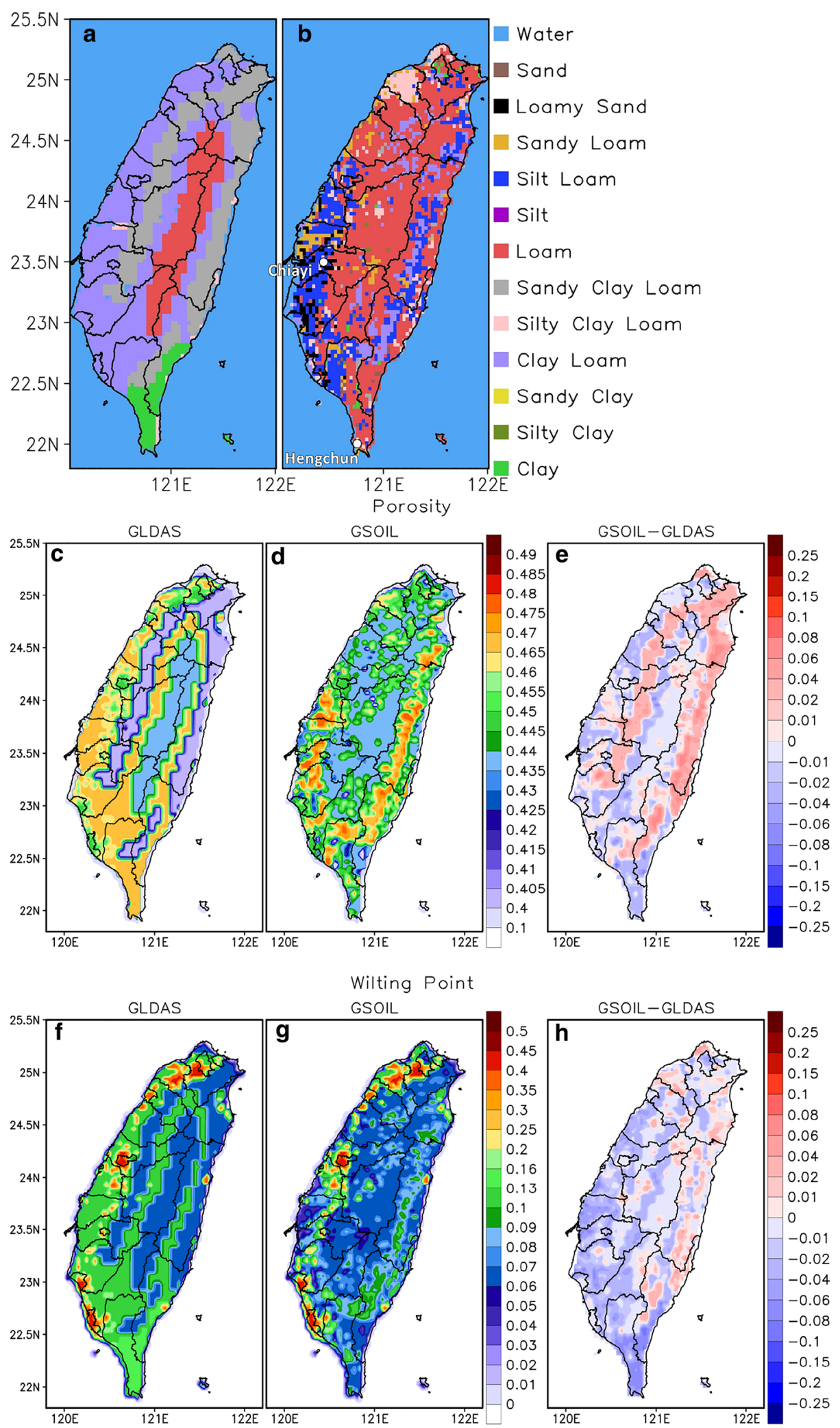

Fig. 3 Distributions of soil textures at 3-km resolution in Taiwan from a default FAO data sets and $\mathbf{b}$ updated soil data. $\mathbf{c}$, $\mathbf{d}$ Porosity based on the look-up table of the default setup and updated soil parameters, respectively; e corresponding difference. $\mathbf{f}-\mathbf{h}$ Are for the wilting point 
NCEP FNL data. In the second WRF sensitivity test, the soil moisture from GLDAS was utilized to provide the soil moisture initialization process (WRF-GLDAS). The third WRF sensitivity test was applied with GLDAS and updated soil textures (WRF-GSOIL).

\section{Model simulation results}

Figure 4 reveals the distributions of volumetric soil moisture $\left(\mathrm{m}^{3} / \mathrm{m}^{3}\right)$ for the top soil layer $(10 \mathrm{~cm}$ thickness $)$ at the initial time (0000 UTC 1 October 2014) from the WRFbase, WRF-GLDAS, and the corresponding differences (a positive value indicates higher from GLDAS data, applied for all the difference plots) at a $3-\mathrm{km}$ grid resolution. The largest difference in soil moisture occurs in the western plain areas. In western Taiwan, the GLDAS data show very dry soil conditions, in which the soil moisture can be lower than $\theta_{\text {wilt }}$ (see Fig. 3). This is a major difference of the current study compared to our previous study (Lin and Cheng, 2016), where the atmospheric condition was wet.

Figure 5 shows the distribution of simulated top-layer soil moisture water contents averaged from the hourly WRF outputs from the 6-month WRF-base simulation results and the corresponding difference between different sensitivities. The WRF-GLDAS simulates lower soil moisture than the WRF-base with major differences occurring in the western low-lying plain areas. The difference between WRF-GLDAS and WRF-GSOIL follows the distributions of the soil type. In western Taiwan, the soil type is classified as clay loam soil based on the default FAO soil data; yet, it is replaced with silt loam or loam soil in the updated soil data. Compared to the clay loam soil, the silt loam soil or loam soil is associated with coarser soil particles. As a result, water infiltrates more rapidly in the soil columns, which leads to reduced soil moisture in the soil layer in western Taiwan from the WRF-GSOIL run.

Figure 6 shows similar to Fig. 5, but displays the simulated LHF and SHF. In western Taiwan, the reduced soil moisture from WRF-GLDAS led to a decrease of LHF and an increase of SHF compared to the WRF-base. The difference in the LHF resembles the difference in soil moisture (see Fig. 5). The difference between WRFGLDAS and WRF-GSOIL shows an interesting result. In western Taiwan, the soil moisture is reduced in the WRFGSOIL simulation, but the LHF is higher. During the simulation period, due to the unusual dry soil conditions, the soil moisture can be lower than $\theta_{\text {wilt }}$ According to Seneviratne et al. (2010), when the soil moisture is lower than $\theta_{\text {wilt }}$, ET becomes independent of the soil moisture content. According to Fig. $3 \mathrm{~h}, \theta_{\text {wilt }}$ of the soil type from the updated soil type is lower than the one from the default

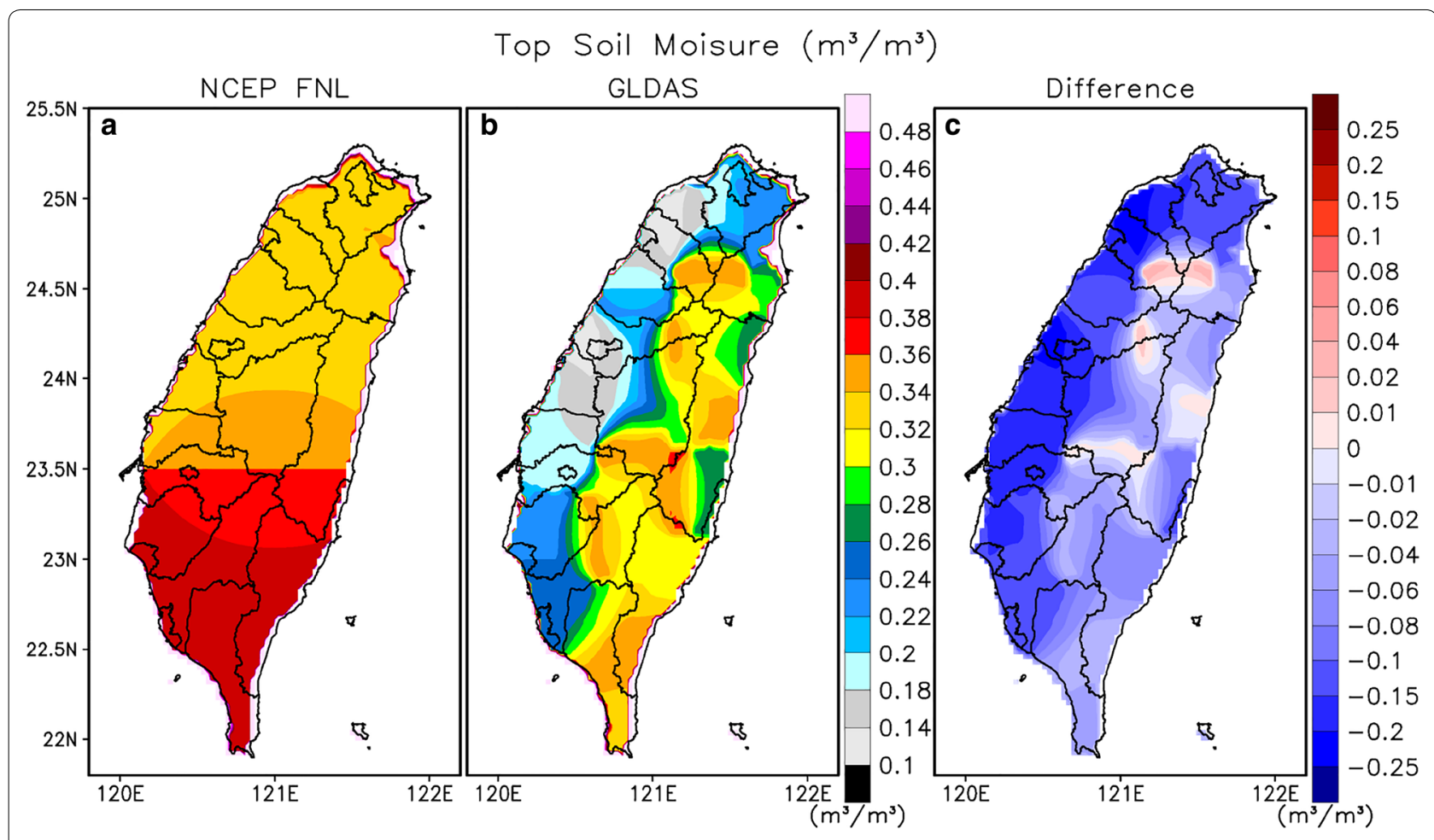

Fig. 4 Top-layer $(0-10 \mathrm{~cm}$ ) soil moisture at 0000 UTC 1 Oct 2014 from a NCEP FNL, b GLDAS, and c corresponding difference 


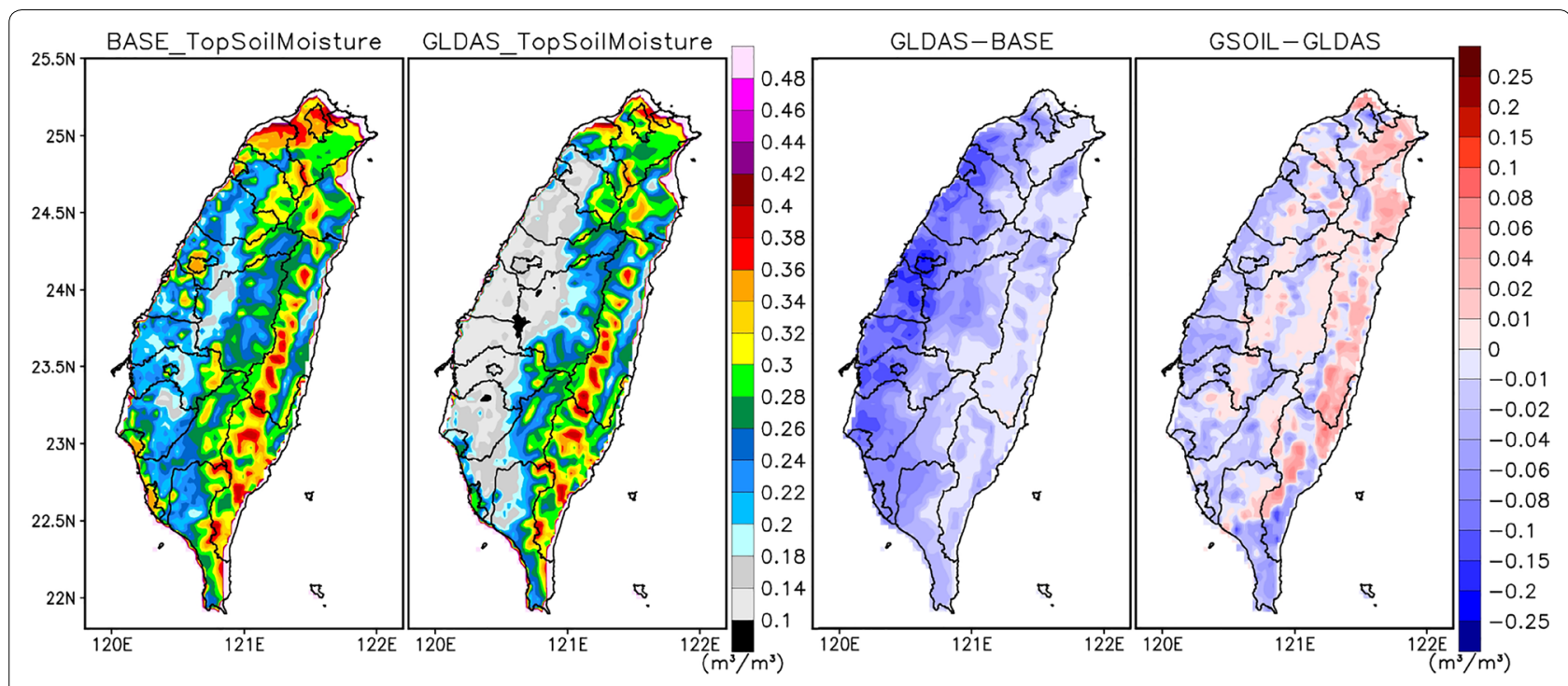

Fig. 5 Top-layer $(0-10 \mathrm{~cm})$ soil moisture $\left(\mathrm{m}^{3} \mathrm{~m}^{-3}\right)$ averaged for 6-month simulation. Left to the right are from WRF-base, WRF-GLDAS, difference between WRF-GLDAS and WRF-base, and difference between WRF-GSOIL and WRF-GLDAS

FAO soil type. If the soil moisture is higher than $\theta_{\text {wilt }}$ of the updated soil type, but lower than $\theta_{\text {wilt }}$ of the FAO soil type, then ET can cease in the WRF-GLDAS run, but still occur in the WRF-GSOIL simulation. Analysis of the ET also indicates higher ET simulated from the WRF-GSOIL simulation (figure not shown). The surface heat flux comparison between WRF-GLDAS and WRF-GSOIL is not like the result conducted in Lin and Cheng (2016) for which two typhoons hit Taiwan, and the atmospheric condition is significantly wet. In Lin and Cheng (2016), the reduced soil moisture in WRF-GSOIL results in lower LHF and higher SHF than the WRF-GLDAS, which exhibits a soil moisture-limited ET regime in which the soil moisture constrains the ET process.

Figure 7 shows the distributions of the sub-surface runoff. The 1-m soil layer underneath serves as a reservoir with a gravitational free-drainage mechanism that generates the sub-surface run-off at the bottom soil layer. The WRF-GLDAS shows a lower sub-surface runoff than the WRF-base run due to the reduced soil moisture content. The distribution of the difference between WRFGLDAS and WRF-GSOIL resembles the pattern of the soil parameters such as the difference in the soil porosity (see Fig. 3f) and saturation hydraulic conductivity (figure not shown) (Lin and Cheng 2016). For example, a sandy clay loam soil is associated with coarse soil particles; with the updated soil classifications, the sandy clay loam is replaced with smaller particle size of soil such as the loamy soils. Soil type with coarse-sized soil particles has a lower soil porosity and higher soil conductivity than fine-sized soil particles; as a result, water infiltrates more rapidly into the sandy clay loam soils and produces a higher sub-surface run-off than that from soil textures with loamy soil type.

Figure 8 shows the distributions of 2-m air temperature and $10-\mathrm{m}$ wind fields. Due to the reduction of the LHF and the increase of SHF, the WRF-GLDAS shows a higher temperature than the WRF-base, which also enhances the wind flow. Alternatively, the WRF-GSOIL shows a lower temperature than the WRF-GLDAS, and the wind speed variation between the two simulations is less apparent. Due to the unusual dry condition, the distinction of the surface fluxes, temperature, and wind fields due to the soil moisture variations is enhanced in the current 6-month drought period compared to the previous 1-month study conducted in Lin and Cheng (2016).

Figure 9 depicts the hourly variations of individual terms [soil water storage $(\mathrm{dS} / \mathrm{dt})$, precipitation $(\mathrm{P}), \mathrm{ET}$, and total run-off (surface run-off and sub-surface drainage)] in the surface water budget equation. The analysis is only conducted for October 2014, because the variation among different simulations becomes less apparent towards the end of the first simulation month. The changes in the storage term appear negative due to the ET and the runoff process, except for the rainfall days. Compared to Lin and Cheng (2016), the magnitude of the ET is strengthened in this study due to the unusual dry soil and atmospheric conditions that enhances the landair interactions. The WRF-GLDAS shows lower ET and runoff compared to the WRF-base due to the reduced 


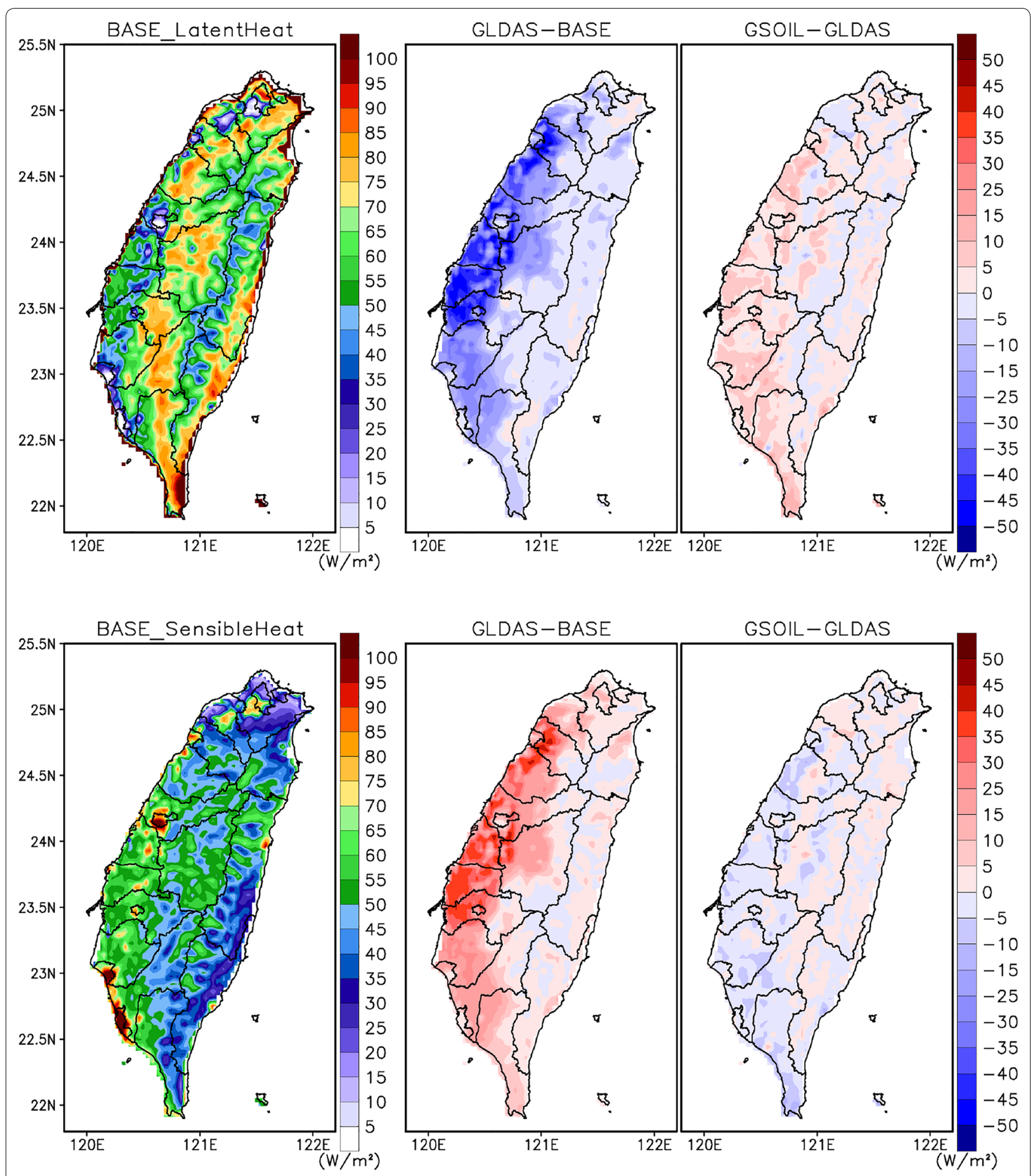

Fig. 6 LHF (top) and SHF (bottom) averaged from 6-month simulation. Left to the right are from the WRF-base run, difference between WRF-GLDAS and WRF-base, difference between WRF-GSOIL, and WRF-GLDAS 


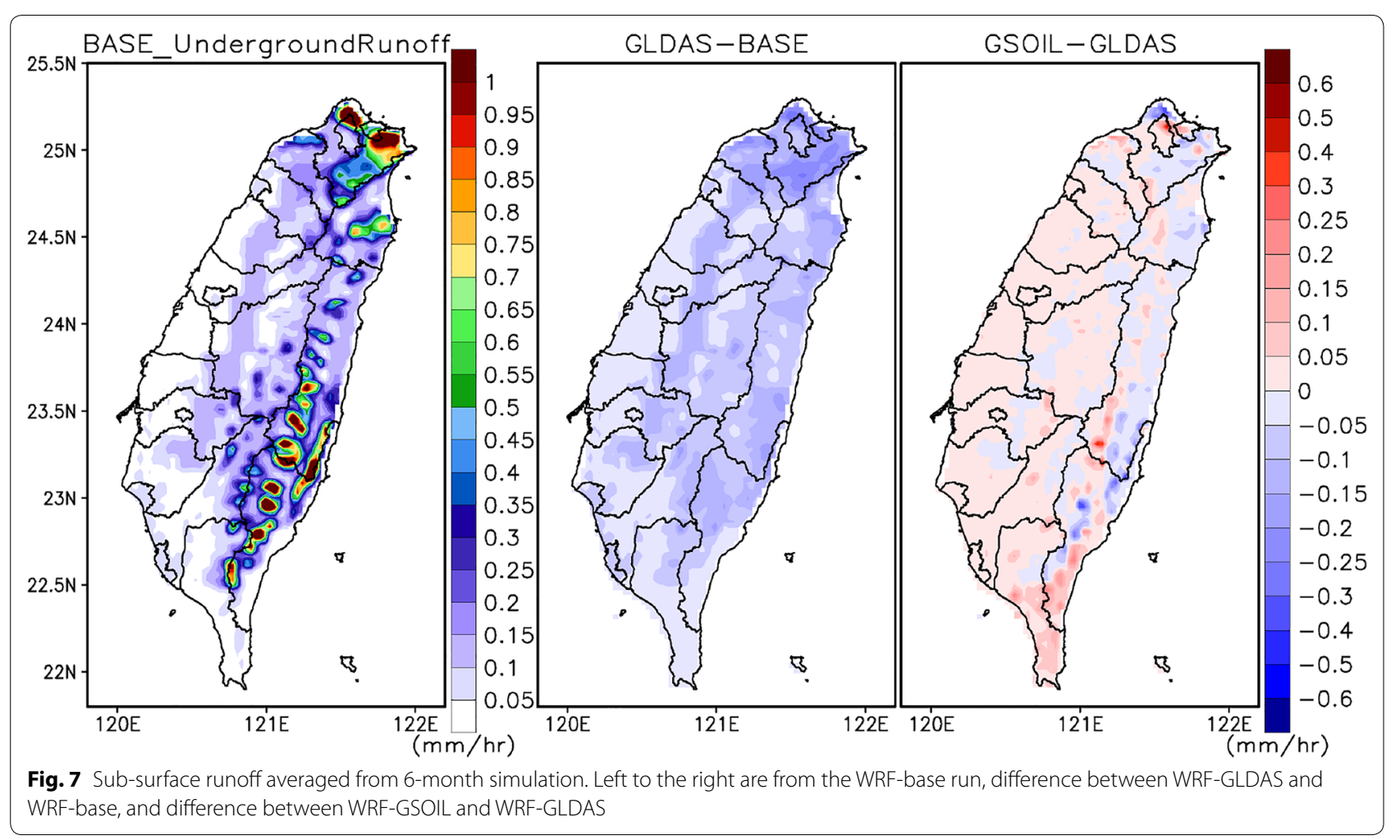

soil moisture. Alternatively, the difference between the WRF-GSOIL and WRF-GLDAS is less apparent.

Finally, the assessment of the simulation results with the observed soil moisture is conducted. Detailed evaluation of the model simulation results has been compared in Chen et al. (2016) and studied in Lin and Cheng (2016). The comparisons here only focus on the soil moisture evaluations. Figures 10 and 11 compare the soil moisture between observations, the WRF-base, WRF-GLDAS, and WRF-GSOIL simulations at Chiayi and Henchun sites, where the observed soil moisture is available and of good quality (see Fig. $3 \mathrm{~b}$ for site location) (Chiang et al. 2015). The comparison is made at the top $(10-\mathrm{cm})$, second $(30-\mathrm{cm})$, third $(70-\mathrm{cm})$, and fourth $(150-$ $\mathrm{cm})$ soil layer. The WRF-GLDAS and WRF-GSOIL show lower soil moisture than the WRF-base and agree better with the observed data, while the WRF-base shows a systematic wet value of soil moisture.

At Chiayi site, the WRF-base shows a gradual drying process towards the end of the simulation period, while the variation of soil moisture in WRF-GLDAS and WRF-GSOIL is not apparent due to the dry soil condition. The observed soil moisture at $10-\mathrm{cm}$ depth shows a very low soil moisture in a range less than $20 \%$ most of the time except for the rainfall days. All the models overestimated the top-layer soil moisture at Chiayi site.
WRF-GLDAS and WRF-GSOIL perform better due to improved initial soil moisture condition. Because Chiayi site is located nearby the rice paddies, the observed soil moisture at the second, third, and fourth soil layers is high and reaches a saturated condition at $150-\mathrm{cm}$ depth. All the models fail to capture the damp soil conditions in deep layers of soil column at Chiayi site that could be due to the improper treatment of the irrigation effects and the interaction between soil layers and the groundwater. For example, the Noah land-surface model only considers a free-drainage lower boundary condition in the bottom soil layer and has no upward groundwater flow into the lowest soil layer (Barlage et al. 2015).

At Hengchun site, all the models overestimated the soil moisture due to too wet initial soil moisture conditions. The gradual drying process throughout the simulation period can be seen from all the simulation results. The soil moisture converges to a similar value towards the end of the simulation period in WRF-base and WRF-GLDAS run at Hengchun site; however, at Chiayi site, due to distinct soil moisture initialization between WRF-base and WRF-GLDAS, the difference of soil moisture is still apparent at Chiayi site even after the 6-month simulation time. Orth and Seneviratne (2012) also indicated that the extremely dry or wet states of the soil tend to increase soil moisture memory. 

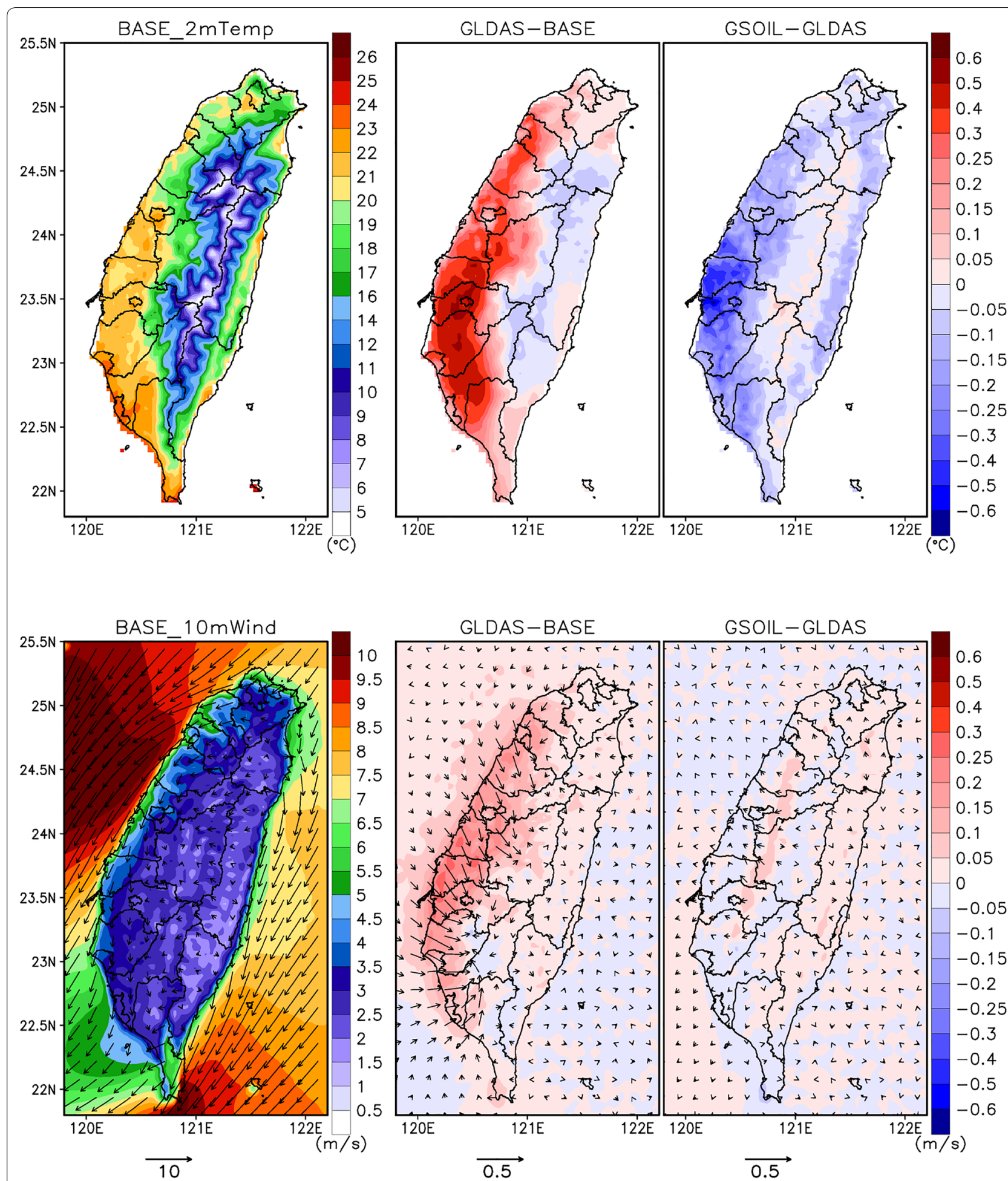

Fig. 8 (Top) The 2-m temperature $\left({ }^{\circ} \mathrm{C}\right)$ and (bottom) 10-m wind fields $\left(\mathrm{m} \mathrm{s}^{-1}\right)$ averaged from 6-month simulation. Left to the right are from the WRF-base run, difference between WRF-GLDAS and WRF-base, and difference between WRF-GSOIL and WRF-GLDAS 

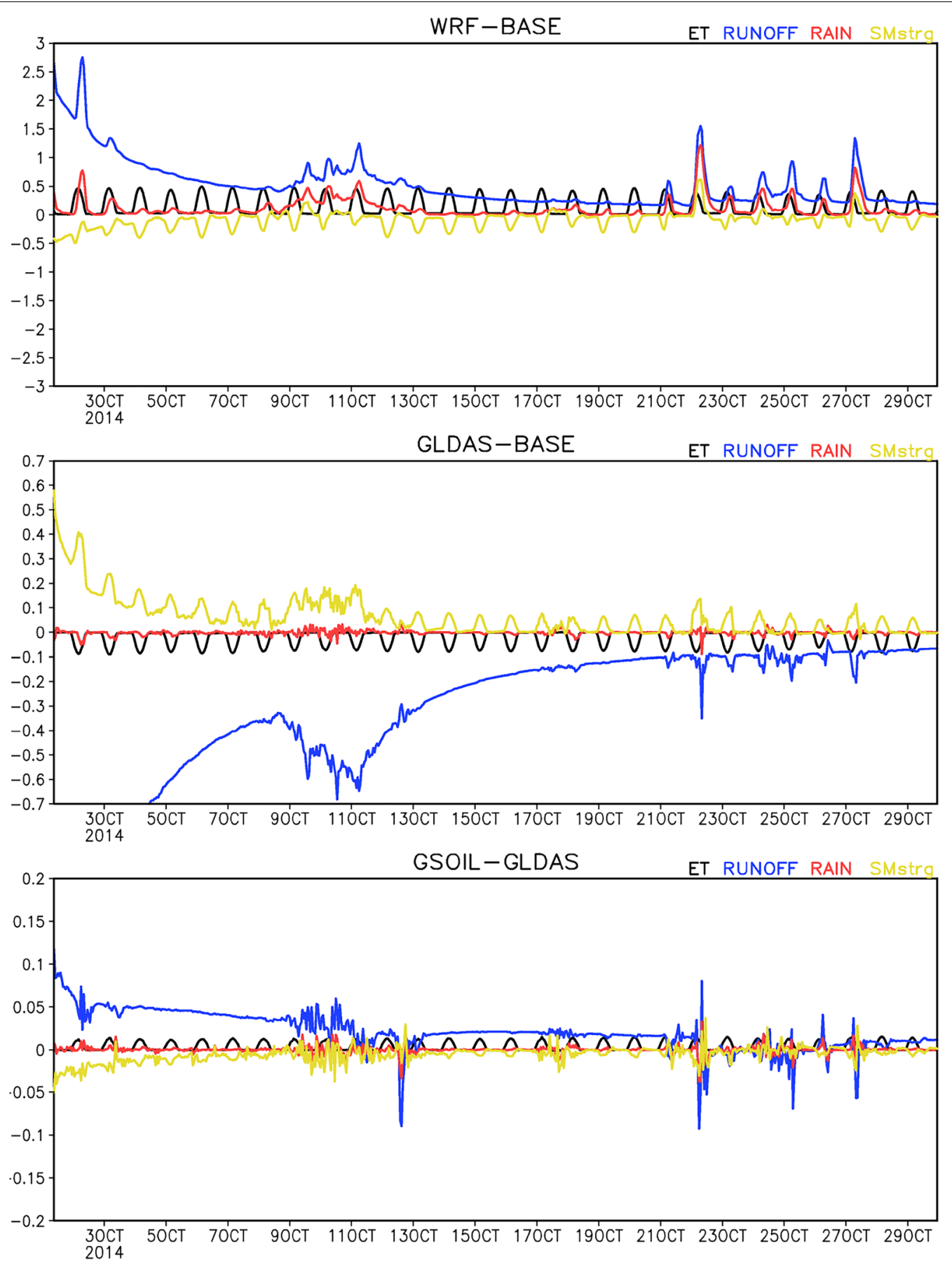

Fig. 9 Hourly variations of individual processes in surface water budget equation $(\mathrm{mm} / \mathrm{h})$ averaged from simulation domain. Top to the bottom, from WRF-base run, difference between WRF-GLDAS and WRF-base and difference between WRF-GSOIL and WRF-GLDAS (yellow line: change in soil water storage; red line: precipitation; black line: evapotranspiration; and blue line: total runoff)

\section{Conclusions}

The soil moisture is a crucial component that affects the land-surface energy and water budgets. It constrains the ET process, which is an important source of water vapor over land, and in turn impacts precipitation.
Moreover, soil moisture is involved in a number of feedbacks through the land-air interactions and land-surface hydrologic cycle.

In our previous study (Lin and Cheng, 2016), we investigated the impact of soil moisture initialization and 

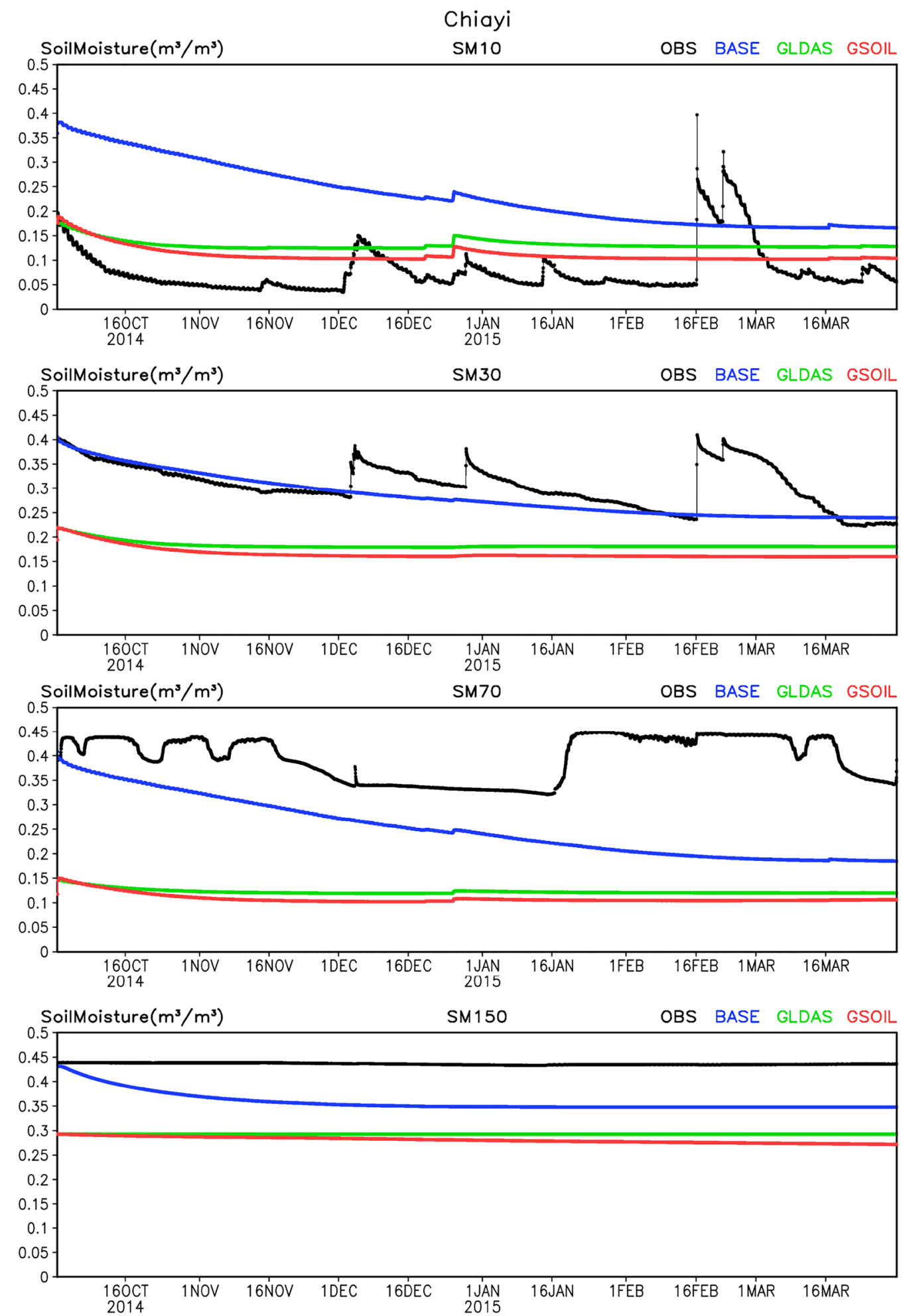

Fig. 10 Soil moisture comparisons from observations and simulations at the Chiayi site. Top to the bottom are at top (10- $\mathrm{cm})$, second (30-cm), third (70-cm), and fourth (150-cm) soil layer (black: observation; blue: WRF-base; green: WRF-GLDAS; red: WRF-GSOIL) 

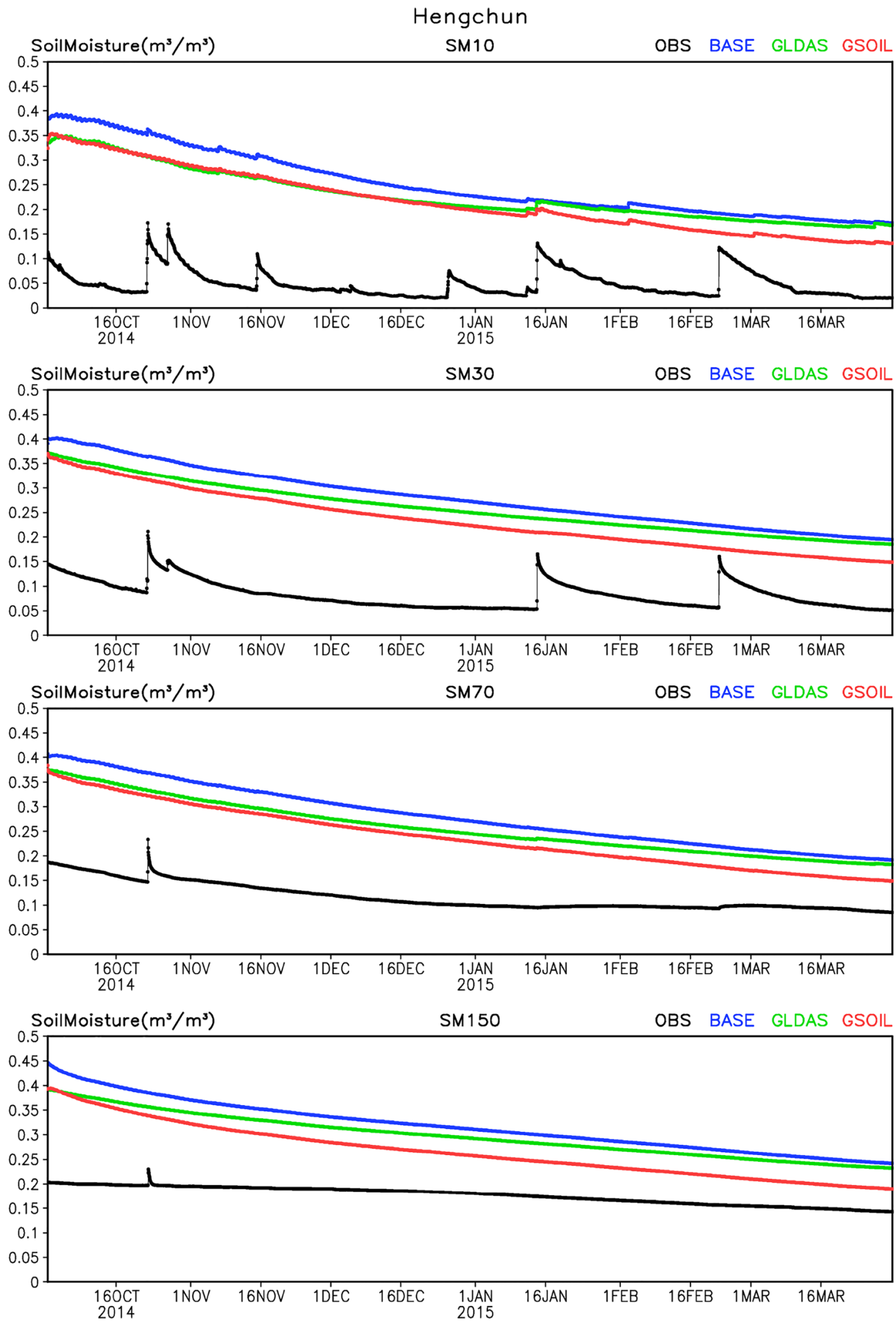

Fig. 11 Similar to Fig. 10 but at Hengchun site 
soil texture on land-air interactions for a short-term 1-month period, in which two typhoons hit Taiwan and the atmospheric condition was wet. The simulation results reveal the importance of soil moisture on the land-air interactions, and showed that the initialization of soil moisture and soil texture can affect the nearsurface meteorological variables. The simulation results indicate a soil moisture-limited ET regime, in which the soil moisture constrains the ET.

In this study, we extend the simulation period to 6 months and target a drought period. During the 6-month study period, the atmospheric condition is dry due to the lack of the rain. Compared to the study of Lin and Cheng (2016), the ET process is strengthened in this study, indicating that the land-air interactions are significant and ET can be an important source of water vapor when the atmospheric condition is dry. A comparison between the WRF-GLDAS and WRF-GSOIL simulations shows that the soil moisture is reduced in WRF-GSOIL in western Taiwan due to the larger size soil particle that has less capability to hold water, which in turn reduces the soil moisture content compared to the WRF-GLDAS result. The soil moisture is lower in western Taiwan from the WRF-GSOIL, but the LHF is increased, which indicates that ET is independent of the soil moisture content. In fact, due to the unusual dry condition in this study period, the soil moisture can be lower than $\theta_{\text {wilt }}$. The supply of $\theta_{\text {wilt }}$ according to the soil look-up table generally becomes lower in the updated soil type; hence, the ET process is still on-going in the WRF-GSOIL simulation, while it can cease in the WRF-GLDAS run once the soil moisture is lower than $\theta_{\text {wilt }}$.

Finally, this study highlights the importance of soil moisture variations for the land-air interactions. In particular, when the atmospheric condition is dry, the soil moisture content and the ET process become significant in the role of the land-surface hydrologic cycle.

\section{Authors' contributions}

Both authors read and approved the final manuscript.

\begin{abstract}
Acknowledgements
This study was conducted under the research project entitled 'Development of high resolution atmospheric modeling and long-term atmospheric data sets in Taiwan and East Asia', supported by the Ministry of Science and Technology, under Grant Number MOST 105-2621-M-008-001. We would like to thank the National Center for High-Performance Computing (NCHC) of Taiwan for providing computational resources and storage resources. We also thank the Central Weather Bureau in Taiwan for providing the surface station data sets and Professor Ben-Jei Tsuang at National Chung-Hsing University for providing the observed soil moisture data sets.
\end{abstract}

\section{Competing interests}

The authors declare that they have no competing interests.

\section{Availability of data and materials}

Not applicable.
Consent for publication

Not applicable.

Ethics approval and consent to participate

Not applicable.

Funding

Not applicable.

\section{Publisher's Note}

Springer Nature remains neutral with regard to jurisdictional claims in published maps and institutional affiliations.

Received: 3 May 2018 Accepted: 9 October 2018

Published online: 25 October 2018

\section{References}

Barlage M, Tewari M, Chen F, Miguez-Macho G, Yang Z-L, Liu GY (2015) The effect of groundwater interaction in North American regional climate simulations with WRF/Noah-MP. Clim Change 129:485-498

Brubaker KL, Entekhabi D, Eagleson PS (1993) Estimation of continental precipitation recycling. J Clim 6:1077-1089

Central Weather Bureau (CWB) (1991) Climatic Atlas of Taiwan, Republic of China. Vol. 1 (Popular Edition), Ministry of Communications, Taipei, Taiwan, Republic of China

Chen F, Dudhia J (2001) Coupling an advanced land-surface hydrology model with the Penn State-NCAR MM5 modeling system. Part I: model implementation and sensitivity. Mon Weather Rev 129:569-585

Chen Y, Cheng F-Y, Li M-H (2016) Impact of the soil moisture change on surface water cycle processes in semiarid season in Taiwan. International workshop on Typhoon and Flood (IWTF) student poster competition, Taipei, Taiwan

Chiang C-H, Chien C-Y, Tsuang B-J, Tang M-L, Li Y-C, Hong J-S, Kuo P-H, Tsai J-L (2015) Establish soil moisture observing network in Taiwan and data analysis. Atmos Sci 43:133-150 (in Chinese with English abstract)

Hung Y-C, Hong J-S, Tsay C-L, Barlage M, Chen F (2014) Evaluation of the high resolution land data assimilation system. Atmos Sci 42:29-47 (in Chinese with English abstract)

Koster RD et al (2004) Regions of strong coupling between soil moisture and precipitation. Science 305:1138-1140

LeMone MA, Chen F, Alfieri JG, Tewari M, Geerts B, Miao Q, Grossma RL, Coulter RL (2007) Influence of land cover, soil moisture, and terrain on the horizontal distribution of sensible and latent heat fluxes and boundary layer structure in southeast Kansas during IHOP_2002 and CASES-97.J Hydrometeor 8:68-87

Leung K-W, Chen T-T (1957) Soils of Taiwan. J Agric Assoc China New Ser 20:1-25

Lin T-S, Cheng F-Y (2016) Impact of soil moisture initialization and soil texture on simulated land-atmosphere interaction in Taiwan. J Hydrometeorol 17:1337-1355

Meng L, Shen YJ (2014) On the relationship of soil moisture and extreme temperatures in East China. Earth Interact 18:1-20

Oki T, Kanae S (2006) Global hydrological cycles and world water resources. Science 313:1068-1072

Orth R, Seneviratne SI (2012) Analysis of soil moisture memory from observations in Europe. J Geophys Res 117:D15115. https://doi. org/10.1029/2011JD017366

Rodell M et al (2004) The global land data assimilation system. Bull Am Meteor Soc 85:381-394

Savenije HHG (1995) New definitions for moisture recycling and the relation with land-use changes in the Sahel. J Hydrol 167:57-78

Seneviratne SI, Lüthi D, Litschi M, Schär C (2006) Land-atmosphere coupling and climate change in Europe. Nature 443:205-209

Seneviratne SI, Corti T, Davin EL, Hirschi M, Jaeger E, Lehner I, Orlowsky B, Teuling AJ (2010) Investigating soil moisture-climate interactions in a changing climate: a review. Earth Sci Rev 99:125-161

Seuffert G, Gross P, Simmer C, Wood E (2002) The influence of hydrologic modelling on the predicted local weather: two-way coupling of a mesoscale 
weather prediction model and a land surface hydrologic model. J Hydrometeor 3:505-523

Skamarock WC, et al (2008) A description of the advanced research WRF version 3. NCAR Tech. Note NCAR/TN-475 + STR. https://doi.org/10.5065/ d68s4mvh

Wythers KR, Lauenroth WK, Paruelo JM (1999) Bare-soil evaporation under semiarid field conditions. Soil Sci Soc Am J 63:1341-1349
Yu PS, Yang TC, Wu CK (2002) Impact of climate change on water resources in southern Taiwan. J Hydrol 260:161-175

Yu PS, Yang TC, Kuo CC (2006) Evaluating long-term trends in annual and seasonal precipitation in Taiwan. Water Resour Manage 20:1007-1023

Zaitchik BF, Santanello JA, Kumar SV, Peters-Lidard CD (2012) Representation of soil moisture feedbacks during drought in NASA Unified WRF (NU-WRF). J Hydrometeor 14:360-367

\section{Submit your manuscript to a SpringerOpen ${ }^{\circ}$ journal and benefit from:}

- Convenient online submission

- Rigorous peer review

- Open access: articles freely available online

- High visibility within the field

- Retaining the copyright to your article

Submit your next manuscript at springeropen.com 